\title{
EXPLAINING THE IMPLEMENTATION MODEL OF GREEN TECHNOLOGY IN IRANIAN AUTOMOBILE INDUSTRY
}

\author{
Mohammad Hossein Kharidar ${ }^{1}$ \\ Manochehr Manteghi ${ }^{2}$ \\ Mahmoud Shirazi ${ }^{3}$
}

\begin{abstract}
Today, the automobile industry plays a critical role in enhancing the transportation level in societies and has become an integral part of human life. Given its direct and indirect interaction with environment in all sectors of production cycle from exploiting the natural resources to manufacturing, production, consumption, and from postconsumption to disposing its wastes, this industry is considered among the major sources of environmental pollution. One of the ways to protect the environment is to institutionalize the use of green technologies in automobile industry, an industry which plays a significant role in this pollution. On the other hand, using green technologies involves the necessary infrastructure in various
\end{abstract}

dimensions which is always facing multiple challenges. The necessary condition to exploit the green technologies is identifying its effective and deterrent challenges which is the focus of this discussion and has been analyzed in two principle phases. In the Phase I, the main framework of the research is formed based on identifying the challenge dimensions, factors and effective indexes according to the presented conceptual model. In the Phase II, given the qualitative nature of research, the Delphi consensus technique is applied. Regarding the consensus obtained by the experts in the first and Phase IIs of Delphi technique, the research process reached its final consensus, thus making it unnecessary to enter into the Phase III. Finally, ten

1 DBA Student in Strategic Management, Department of Management, Iran University of Industries and Mines

${ }^{2}$ Associate Prof., Department of Management and soft Technology, Malek-Ashtar University of Technology

3 Assistant Prof., Department of Management, Iran University of Industries and Mines. Corresponding Author: Mohammad Hossein Kharidar 
environmental and internal challenging factors along with 25 indexes from their subsets were confirmed by the experts, which was used as the basis for the inference and explanation of green technology implementation in the automobile industry.

Keywords: Green Technology, Green automobile Industry, Challenges in Exploiting the Green Industry

\section{Introduction}

The development of technology and innovations in the domain of industry has led to formation of competitiveness paradigm as a critical and multidimensional index in various industries, so that it is today necessary to give special attention to competiveness as an effective and critical factor, in a way proportionate and aligned with technology growth in international arena, because in international interactions- i.e., globalization- any unsuitable programming can potentially bring the new technologies into failure. Also the development of green technology in the one hand and the challenges of applying it inside and outside of an organization either in terms of technology transfer or providing the required infrastructures on the other hand, are the relevant theoretical foundations considered today by the industrial societies in both developed and developing countries.

The emphasis of Iranian managers on environmental issues, the necessity of interacting with the international communities, making the necessary infrastructures to join to the World Trade Organization (WTO) and raising the competitive edge relative to imported products are among the issues which lead the Iranian industries including the automobile industry towards applying the green technology.

In other words, a qualified and sophisticated organization should be able to adapt with the environmental rules. Such an organization can understand the environment, prepare the necessary information and knowledge, be agile in responding, be a suitable base for innovation and creativity, learn from lessons and revise its structurers.

Industrial development is one of fundamental components for development of countries. In the competitive world of today, industries possess a strategic status, as progress in 
this field not only causes increased production and employment, but also facilitates service provision and leads to increased productivity in other sectors.

Perhaps no one in the past could see that someday the health of society and consumer gains as much interest as the profitability and sales. However, the dynamics and severe competitions as well as the increased concerns on environment and also the governmental and international regulations along with increased knowledge of consumers led the companies to reflect on the mental and physical health as well as the cleanness of the consumer environment [3].

Given the increased environmental laws and regulations as well as public awareness, the contemporary companies should not ignore these issues if they want to survive in the world market [4]. Understanding the fact that the environmental effects are not only limited to the final phase of production led the attentions towards the environmental issues not only in production operation but throughout whole supply chain [5].
Globalization, increased governmental and nongovernmental organizations and the pressure from public knowledge regarding the environmental issues led the organizations to investigate the needed actions in order to exploit the green technologies for enhanced environmental and economic performance [6].

The automobile industry as an old, important industry which is predicted to constitute at least a gross production value of $4 \%$ in 2025 is both in direct and indirect interaction with the environment in all parts of its life cycle from exploiting the natural sources to manufacture, production, consumption and post-consumption.

In our country, unfortunately due to resource endowment, the production process has remained mostly unattended; we have been always waiting for others to think for us in producing new products and processes, this leading us to obtain and apply the obsolete and outdated results.

Surviving in a highly competitive age requires inevitably continuous improvement of related products and services in all dimensions 
so as to make it possible to compete with the foreign powerful competitors. One such country currently having a special place in automobile industry is South Korea, which has dominated the world markets, particularly the markets in developing countries. Evidently, this success owes to abilities and opportunities provided for automobile manufacturing companies [8].

In this research, by explaining a model, the author aims to identify the factors effecting the exploitation of green technologies in automobile industry and presents the exploitation model of green technology in automobile industry.

\section{Problem Statement}

Given the changes occurring in attitudes and general culture of society (albeit with a slow rate), domestic laws and international requirements, the movement of industries including the automobile industry- as a most widely consumed production in society, towards green technology is inevitable.

In other words, the contemporary industries would not be able to survive in absence of customer relationship and understanding their opinions and attitudes on their good performance as well as without attending to the social and environmental responsibilities.

In the other hand, dependency of the country's revenue to petroleum and its lower non-petroleum exportations are the source of its economic problems. As the automobile industry has a high potential, it can be expected that the growth and reinforcement of this industry along with enjoying the green technology can help to increase the employment level and flourishing of the internal markets as well as show higher effectiveness in regional competition, thus have a higher share as a non-petroleum good in exports of the country. For this purpose, the role of up to date standards and innovations should be considered, whether in production of parts to enhance the safety level and convenience, or in exploiting the technologies which protect the environment.

It is worth mentioning that the all issues in terms of performance from customers' and social observer's perspective and environmental aspects are being judged. Success in determined 
by manufacturers but also by the customers and observers.

In this research we attempt to identify the most important elements and challenges in exploiting the green technology in Iran's automobile industry. Accordingly, in order to realize the goals, it is necessary to identify the capabilities and apply the international environmental regulations. Although the atmosphere governing our country's automobile industry very different from that of developed countries, this distance can be reduced using the present experiences in a short time.

In fact, being aware of the factors can help the managers in this industry as decision makers to understand the environmental issues relevant to the industry and include them in the company's objectives and strategies so as to can achieve higher share in the market, increase their profitability and even protect the company against the failures.

Also the valuable teachings of Islam put emphasize on subject of environment and the way humans interact and adapt themselves to it. The constitution of the Islamic Republic of Iran also considers environmental protection as a public responsibility, where the growth and excellence of current and future generations depends on protection of resources.

"In the Islamic Republic, the protection of environment is considered a public responsibility, in which the current and future generation should live an evolving social life. Therefore, any activity incurring irremediable damage to environment shall be forbidden".

The term "resistive economy" refers to reduced vulnerability against threats and damages. As a result, it does not only imply a defensive and passive meaning; but there is now an emerging concept of economic resiliency for the organizations. In fact, the concept of resiliency refers to avoidance from some risks and restrain others. And in case facing the risk, it is necessary for organizations to reach to needed stability by returning to the desirable conditions and using the existing opportunities.

Also the other necessity in dealing with this subject originates from increased environmental awareness.

The environmental processes, including the processes to supply raw material, design, manufacture, use and recycling and reuse (creating a closed 
loop) are material flow to reduce the resource consumption and the damaging environmental effects [7]. Therefore, the organizations should apply the environmental management in all lifecycles of their products so as to ensure the improvement of environmental performance.

One fact necessitating this study in Iran is that he deputy of Iranian human environmental protection organization stated that based on the statics from the world bank, the damages from air pollution in 2006 in Iran amounted to 8 billion dollars, reaching to 16 billion dollars in 2016 [6], which would be essentially significant in case of continuing the current trend.

\section{Literature review}

One of the basic components of growth and development in any country is its industrial development. The strategic status of industries in the competitive world of today is evident for anybody, as the development in this field leads not only to increased production and employment but also facilitates the service supply and increase productivity in other sectors. Evidently, the automobile industry has contributed as a driving force for the economic growth in the $20^{\text {th }}$ century. The automobile industry and its related activities, from the steel industries, rubber manufacturing, parts manufacturing and glass manufacturing to after-saleservices, recycling the old cars etc. have been among the most widespread and profitable economic networks. Forty years ago, Peter Drucker (1909-2005) called the automobile industry as "the industry of industries." With offering more than 65 million vehicles, the automobile industry still faces 20 million over-capacities per year. The 28 percent profit reduction besides of early increased production indicates the heavy competition to protect or increase the market share through decreased profit and increased productivity and development of automobile electronics section.

In sum, it should be acknowledged that the automobile industry is has significant role regarding the importance and extensiveness of its related industries, generating employment, applying high techs, development indexes, profitability, intensive competition in production and business. The cultural 
and social implications from development in this industry on human societies, including welfare, diversity, entertainment, sports, is still widespread.

However, the contribution of governments in supporting the automobile industry should be considered due to its high significance and stance in the international economy. It is worth reminding that during the world economy crisis, the loud voice of automobile industry was heard first from banks and then via media. Subsequently, the governments rushed to save this industry without any hesitation.

The automobile industry has played role in the economic destination of most countries, acting as the driving force for transportation, business, employment, innovation, technology and economical restoration. The positive, permanent and remarkable growth of automobile manufacturing in the postworld war II offered a signifcant economic growth to the market and world economy, thus transformed the welfare level of societies.

The final status of automobile components is of high significance for car designers. In Germany, for example, it is awaiting the adoption of the law on the responsibility of the automobile manufacturers to return and recycle vehicles, similar to the one currently in place for the recovery and recycling of product packaging.

The vision of this law has already created a momentum in the German car company by creating some strategies to decrease the number of different types of plastic used in the car and "design for disassembly" to facilitate the economic recycling of worn-out vehicle parts by designers. It is anticipated that such regulations may be introduced in the United States.

In the current conditions, it is not possible to recycle more than $25 \%$ of a vehicle (one third of types of plastic including 20 different types - about 220 pounds- one-third rubber and other elastomers, and one-third glass, textile and liquids) and it is generally can be buried.

In the USA, this automobile waste constitutes 1.5 percent of total municipal waste. These wastes sometimes contain heavy metals, oils and other dangerous materials.

In future, the alternative driving force system can create new concerns about recycling. For example, many 
electrical vehicles are produced and sold which are made of lead acid batteries, causing remarkable lead extension into the environment. Other stranger types of batteries such as Sodium sulfur, nickel metal hydride, or lithium polymer can increase new issues regarding recycling and disposal (10).

The Conceptual Research Model

Using the results from literature review and with the aim of exploiting the green technology in Iranian automobile industry, the conceptual model (detailed) is as follows. 


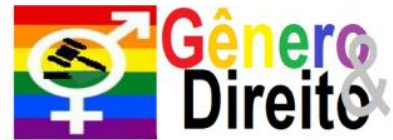

Periódico do Núcleo de Estudos e Pesquisas sobre Gênero e Direito

Centro de Ciências Jurídicas - Universidade Federal da Paraíba

V. 9 - $\mathrm{N}^{\circ} 02$ - Ano 2020

ISSN | 2179-7137 | http://periodicos.ufpb.br/ojs2/index.php/ged/index

\section{Research Methodology}

The environmental challenges effecting the exploitation of green technology in automobile industry

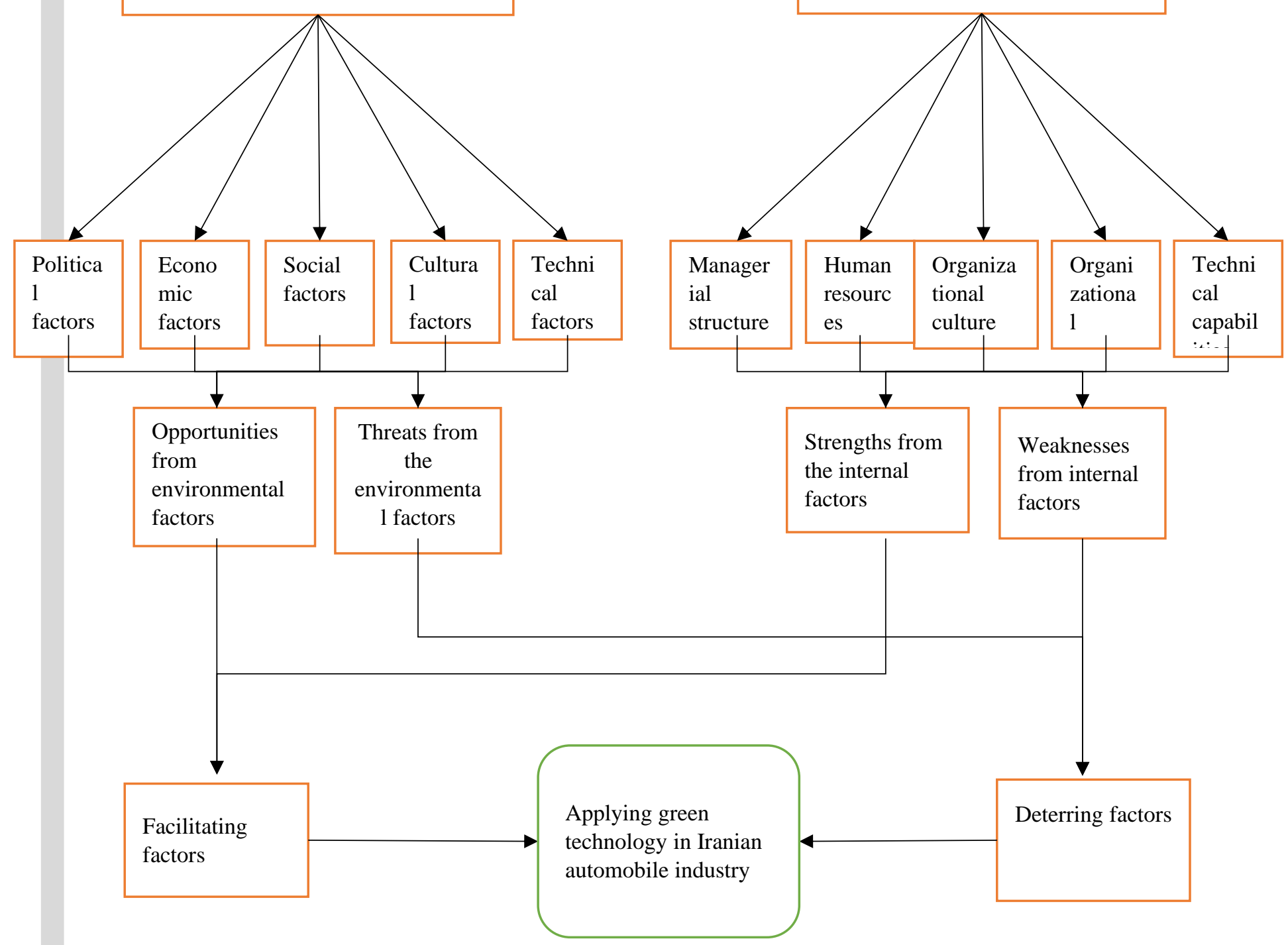

The internal challenges effecting the exploitation of green technology in automobile industry 
The present research aims to identify the most important challenges effecting the green technology in Iranian automobile industry. For this reason, as shown in the initial research proposition, the Delphi technique was used as an acceptable tool in qualitative statistical analysis.

In this research, with respect to the content and heuristic method predicted in research and being qualitative, the statistical population included the following subjects: professionals and experts of Iranian automobile industry, university professors in relation with the subject, automobile experts of environmental protection organization. The sampling method is also a non-probability or selective (purpose-based) sampling from this population. Library studies and questionnaire tools were used to collect data. Considering the nature of the research (qualitative) and its data analysis (Delphi technique), a questionnaire consisting of three options (low, medium and high) was used to obtain the opinions of experts in the automobile industry and the automobile sector of the environmental protection organization and active university professors. With regard to the qualitative research, the descriptive statistical method was used.

\section{Research Findings}

In the Delphi Phase I technique, out of the 27 participants in the specialized panel, 21 subjects responded to the questionnaires (78\%).

Given the number and quality of the panel members mentioned, these numbers and their results are acceptable and are the basis of research evaluation.

In addition to the selection of expert panel members, their challenging factors and indexes was selected for questionnaire after reviewing articles, conferences, commentaries, and so on, and after doing the necessary modifications by the research team.

The first questionnaire was designed so that contain an introduction to the research and the personal information for the members of specialized panel along with a spectrum of three-parted response (low equal to "3"m medium equal to " 3 " and high equal to "5").

In other words, the questionnaire evaluation section consisted of 33 questions and was 
designed in ten internal and external domains (factors) respectively as follows: political and governmental challenges ( 7 indexes), economic challenges (4 indexes), social challenges (3 indexes), cultural challenges (2 indexes), technical and technological challenges ( 2 indexes), management structure (4 indexes), human resources (3 indexes), organizational culture (2 indexes), organizational structure (3 indexes), technical and technological capabilities ( 3 indexes)

Also some open space for presenting complementary propositions and the opinion of participants on indexes were included in the questionnaire. The members of the specialist panel then were asked to include their views and observations in the place for the open-ended questions and write the amount of their agreement of the indexes in the mentioned scale by giving scores to questionnaire indexes.

At this phase, according to the consensus obtained on 33 indexes, 24 indexes were accepted with the agreement above 75\%. No indexes subject to the agreement below $25 \%$ and were not excluded and therefore 9 indexes were transferred to the Phase II questionnaire. In addition, four suggested indexes were added at this phase that were added to the Phase II questionnaire.

The results of the Phase I are summarized in below table.

Table 8: Number of accepted, excluded, residual, and normal indexes in Delphi Phase I

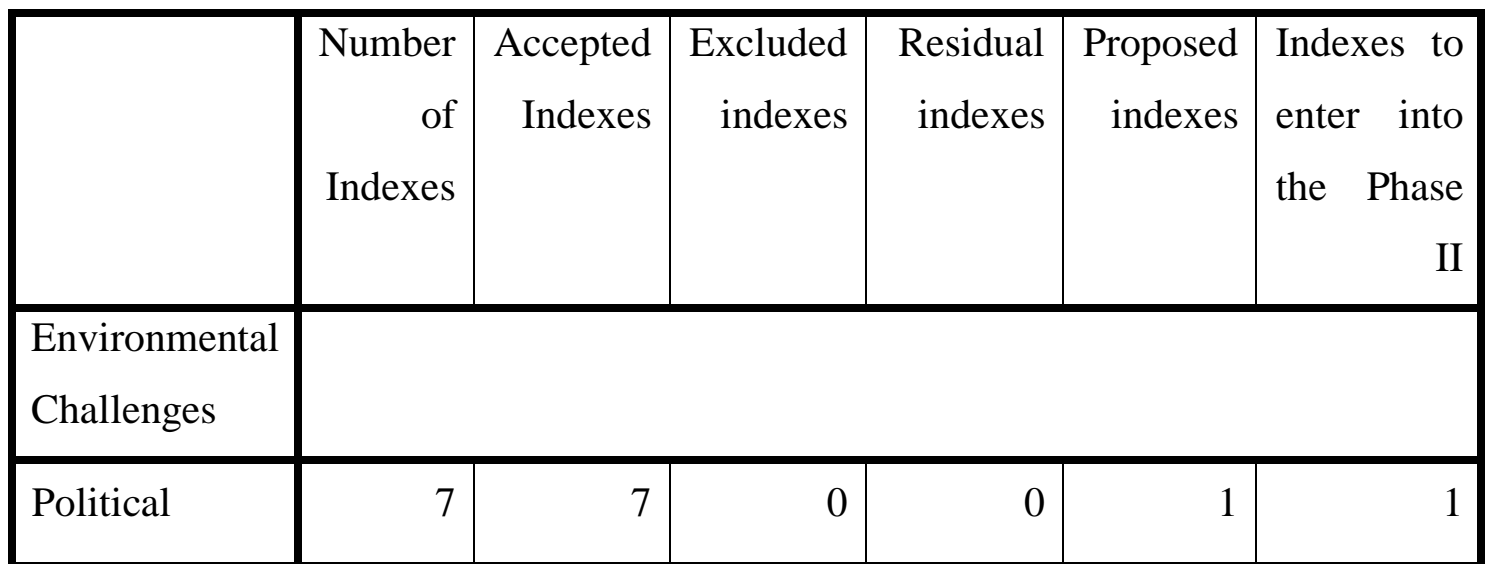




\begin{tabular}{|c|c|c|c|c|c|c|}
\hline Economic & 4 & 3 & 0 & 1 & 0 & 1 \\
\hline Social & 3 & 3 & 0 & 0 & 2 & 2 \\
\hline Cultural & 2 & 1 & 0 & 1 & 0 & 1 \\
\hline $\begin{array}{l}\text { Technological } \\
\text { and technical }\end{array}$ & 2 & 2 & 0 & 0 & 1 & 1 \\
\hline \multicolumn{7}{|l|}{$\begin{array}{l}\text { Internal } \\
\text { challenges }\end{array}$} \\
\hline $\begin{array}{l}\text { Managerial } \\
\text { structure }\end{array}$ & 4 & 2 & 0 & 2 & 0 & 2 \\
\hline $\begin{array}{l}\text { Human } \\
\text { resources }\end{array}$ & 3 & 2 & 0 & 1 & 0 & 1 \\
\hline $\begin{array}{l}\text { Organizational } \\
\text { culture }\end{array}$ & 2 & 1 & 0 & 1 & 0 & 1 \\
\hline $\begin{array}{l}\text { Organizational } \\
\text { structure }\end{array}$ & 3 & 1 & 0 & 2 & 0 & 2 \\
\hline $\begin{array}{l}\text { Technical and } \\
\text { Technological } \\
\text { capabilities }\end{array}$ & 3 & 2 & 0 & 1 & 0 & 1 \\
\hline Total & 33 & 24 & 0 & 9 & 4 & 13 \\
\hline
\end{tabular}

The Delphi Phase II

At this phase, the Phase II questionnaire was sent after inserting the results of the Phase I (accepted indexes, mean agreement obtained with expert panel member evaluation on each of the remaining indexes, and proposed indexes of the Phase I), specifically to 21 individuals from panel members who participated in the Phase I.

Of the 21 respondents in the Phase II specialized panel, 16 respondents responded to the questionnaires (76\%). As noted above, given the number and quality of panel members, this number and the results 
obtained are also acceptable and are the basis for evaluating the present study.

Summary of Delphi Phase II

At this phase, according to the consensus of the 13 indexes that entered this phase, only one index with a high agreement of $75 \%$ was accepted. Other indexes, as mentioned above, were excluded in this phase and thus were not included in the Phase III. The results of the Phase II summary are presented in the table.

Table 9: Number of accepted, excluded, residual, and normal indexes in Delphi Phase II

\begin{tabular}{|c|c|c|c|c|c|c|}
\hline & $\begin{array}{l}\text { Number } \\
\text { of } \\
\text { Indexes }\end{array}$ & $\begin{array}{l}\text { Accepted } \\
\text { Indexes }\end{array}$ & Deleted & $\begin{array}{l}\text { Residual } \\
\text { indexes }\end{array}$ & $\begin{array}{l}\text { Proposed } \\
\text { indexes }\end{array}$ & $\begin{array}{l}\text { Indexes to } \\
\text { enter the } \\
\text { Phase II }\end{array}$ \\
\hline \multicolumn{7}{|l|}{$\begin{array}{l}\text { Environmental } \\
\text { Challenges }\end{array}$} \\
\hline Political & 8 & 7 & 1 & 0 & 0 & 0 \\
\hline Economic & 4 & 3 & 1 & 0 & 0 & 0 \\
\hline Social & 5 & 4 & 1 & 0 & 0 & 0 \\
\hline Cultural & 2 & 1 & 1 & 0 & 0 & 0 \\
\hline $\begin{array}{l}\text { Technological } \\
\text { and technical }\end{array}$ & 3 & 2 & 1 & 0 & 0 & 0 \\
\hline \multicolumn{7}{|l|}{$\begin{array}{l}\text { Internal } \\
\text { challenges }\end{array}$} \\
\hline $\begin{array}{l}\text { Managerial } \\
\text { structure }\end{array}$ & 4 & 2 & 2 & 0 & 0 & 0 \\
\hline $\begin{array}{l}\text { Human } \\
\text { resources }\end{array}$ & 3 & 2 & 1 & 0 & 0 & 0 \\
\hline $\begin{array}{l}\text { Organizational } \\
\text { culture }\end{array}$ & 2 & 1 & 1 & 0 & 0 & 0 \\
\hline
\end{tabular}




\begin{tabular}{|l|l|l|l|l|l|l|}
\hline $\begin{array}{l}\text { Organizational } \\
\text { structure }\end{array}$ & 3 & 1 & 2 & 0 & 0 & 0 \\
\hline $\begin{array}{l}\text { Technological } \\
\text { capabilities }\end{array}$ & 3 & 2 & 1 & 0 & 0 & 0 \\
\hline Total & 37 & 25 & 12 & 0 & 0 & 0 \\
\hline
\end{tabular}

It is noted that out of a total 37 indexes out of ten challenging titles, 25 indexes were consensually over $75 \%$ and 12 indexes were removed due to lack of consensus. In other words, the evaluation of challenging research indexes in Delphi Phase II has finally been achieved and the need to enter Delphi Phase III has been eliminated.

It can be inferred that, for the following reasons, the experts reached a consensus and consensus in the Delphi Phase II:

$$
\text { 1- The anticipated }
$$
characteristics and challenges of past studies and research, and the views of experts in the field of automobile industry were derived from practically expert panel experts.

2- Experts from the panel of experts in all three sets of statistical populations (automobile industry, environmental organization, and university) had relatively similar views on the challenges of the research topic.

\section{Summery}

In analyzing the results according to the description of nature and quality of Delphi, obtaining the opinions of 21 experts in the first round and 16 people in the second round in the expert panel were desirable and the obtained results had a good and acceptable level. Given that the Phase I questionnaire was drawn from papers, conferences, opinions of experts and domestic and foreign experts and considered almost all their points of view, the results obtained from the Phase I (a significant number of accepted indexes and the lower number of suggested indexes) were not far from expectation.

The other feedback included the development of the Phase I questionnaire as described above, that no indexes were 
removed due to poor evaluation, indicating that all indexes are of expert concern but not prioritized.

In other words, in the Phase I, about $73 \%$ of the indexes were agreed and agreed by the experts. In the Phase II, only one of the four proposed indexes was approved by the experts. The results of the Phase II study indicate that the experts were almost constant on their first theory and no significant change was made at this phase.

This consistency of opinion reflects the consensus of the experts that the researcher seeks to achieve. In other words, experts in two phases of the Delphi technique screened the proposed and proposed challenge indexes, followed by eliminating a range of those that were not prioritized, and adopted a relatively favorable range.
Finally, by conducting library studies and receiving expert opinions, the most important features of green technology challenges in the automobile industry were identified and introduced.

Summary and Approval of Final Indexes

As noted, the results of the Delphi process and consensus process resulted in the acceptance of a range of the above indexes, which are presented as a result of the research and the answer to the research questions.

A: Identify and approve the most important environmental indexes and challenges

Approved indexes along with expert agreement percentages and averages based on the maximum score of "5" are presented in Tables 1-5 to 5-10 with titles of environmental challenge subsets.

Political and Governmental Challenges

Table 10: Approved indexes of "Political and Governmental Challenges" from Delphi technique

\begin{tabular}{|l|l|r|r|}
\hline Item & C1: Political and Governmental Challenges & Percentage & Average \\
& & of & Score \\
& & consensus & \\
\hline
\end{tabular}




\begin{tabular}{|r|l|r|r|}
\hline I1 & $\begin{array}{l}\text { Green technologies being effected from the unity of } \\
\text { opinion in the upstream institutions of the automobile } \\
\text { industry }\end{array}$ & 100 \\
\hline I2 & $\begin{array}{l}\text { The effects of sanctions on international technology } \\
\text { partnerships for green technology application }\end{array}$ & 85 \\
\hline I3 & $\begin{array}{l}\text { Lack of access to green technology application } \\
\text { standards and infrastructure }\end{array}$ & 77 \\
\hline I4 & $\begin{array}{l}\text { The challenges of changing domestic laws and } \\
\text { policies on green technologies application }\end{array}$ & 3.86 \\
\hline I5 & $\begin{array}{l}\text { Lack of attention to focal points with the use of green } \\
\text { technologies in the automobile industry }\end{array}$ & 8979 \\
\hline I6 & $\begin{array}{l}\text { Absence of product expiration laws at the end of life } \\
\text { I7 }\end{array}$ & $\begin{array}{l}\text { Non-payment of government subsidies in line with } \\
\text { utilization of green technologies }\end{array}$ & 84 \\
\hline Average political and governmental challenges & 4.48 \\
\hline
\end{tabular}

The consensus of experts shows that the indexes of political and governmental challenges are influenced by the seven effective indexes as described in the table above. The number and variety of characteristics, as illustrated in Figure 1, illustrate the extent and magnitude of the impact of political and governmental challenges in utilizing green technologies in Iran's automobile industry.

Diagram 1: Indexes of political and governmental challenges 


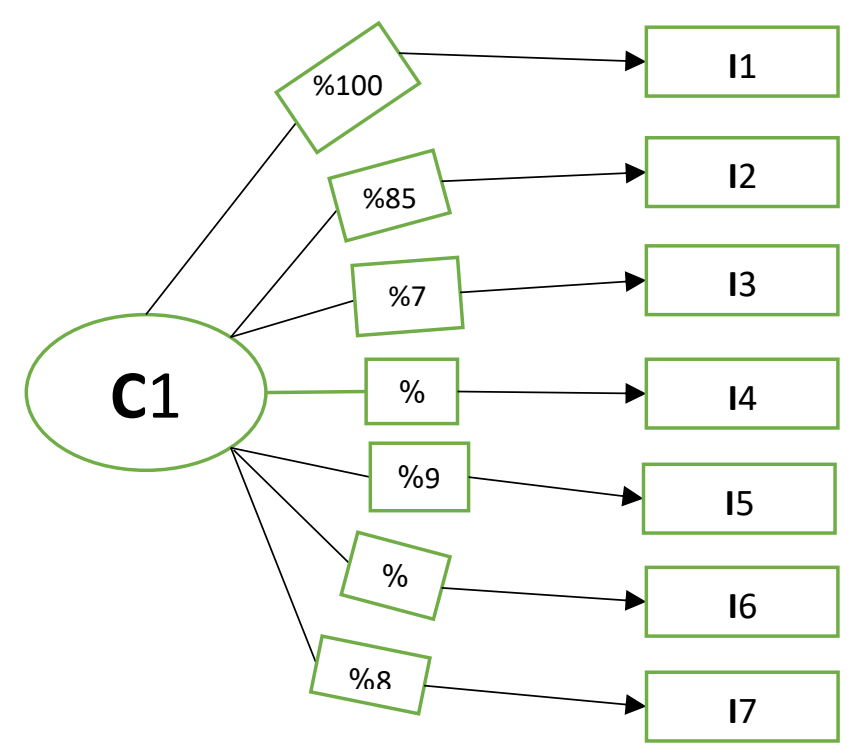

Economic Challenges

Table 11: Approved Indexes of "Economic Challenges" obtained from Delphi technique

\begin{tabular}{|l|l|l|l|}
\hline Item & C2: Economic Challenges & $\begin{array}{l}\text { Percentage } \\
\text { of } \\
\text { consensus }\end{array}$ & $\begin{array}{l}\text { Average } \\
\text { Score }\end{array}$ \\
\hline I8 & $\begin{array}{l}\text { Lack of research funding for green technologies in the } \\
\text { automobile industry }\end{array}$ & 87 & 4.33 \\
\hline I9 & $\begin{array}{l}\text { Financial constraints; effective implementation of } \\
\text { green technology strategies in the automobile industry }\end{array}$ & 89 & 4.43 \\
\hline I10 & $\begin{array}{l}\text { High cost / finished price (competitive price) of } \\
\text { utilizing green technologies }\end{array}$ & 86 & 4.29 \\
\hline & Average economic challenges & & 4.35 \\
\hline
\end{tabular}

The consensus of experts shows that economic challenges are influenced by the three effective indexes described in the table above. The number and 
variety of characteristics, also illustrated in Figure 2, illustrate the extent to which economic challenges can be exploited to exploit green technologies in Iran's automobile industry.

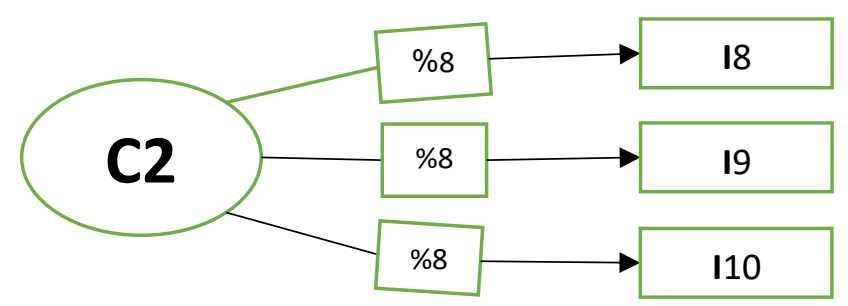

Diagram 2: Economic Challenges Indexes

Social Challenges

Table 12- Approved Indexes of "Social Challenges" obtained from Delphi technique

\begin{tabular}{|c|c|c|c|}
\hline Item & C3 : Social Challenges & $\begin{array}{l}\text { Percentage } \\
\text { of } \\
\text { consensus }\end{array}$ & $\begin{array}{l}\text { Average } \\
\text { Score }\end{array}$ \\
\hline I11 & $\begin{array}{l}\text { Inappropriate mentality and low credibility of Iranian } \\
\text { green technology products compared to products from } \\
\text { other foreign companies }\end{array}$ & 81 & 4.05 \\
\hline $\mathrm{I} 12$ & $\begin{array}{l}\text { Unfavorable business environment and unstructured } \\
\text { import of cars with green technology }\end{array}$ & 83 & 4.14 \\
\hline I13 & $\begin{array}{l}\text { Not having a well-known brand with and } \\
\text { internationally independent Iranian identity }\end{array}$ & 83 & 4.14 \\
\hline I14 & $\begin{array}{l}\text { Lack of adequate relationship between universities and } \\
\text { knowledge-based companies regarding the use of } \\
\text { green technologies }\end{array}$ & 75 & 3.75 \\
\hline & Average social challenges & & 4.02 \\
\hline
\end{tabular}

The consensus of the experts shows that the social challenges are influenced by four attributes as shown in above Table. The number and variety of 
attributes, as illustrated in the diagram, show the magnitude of the impact of social challenges in utilizing green technologies in the automobile industry.

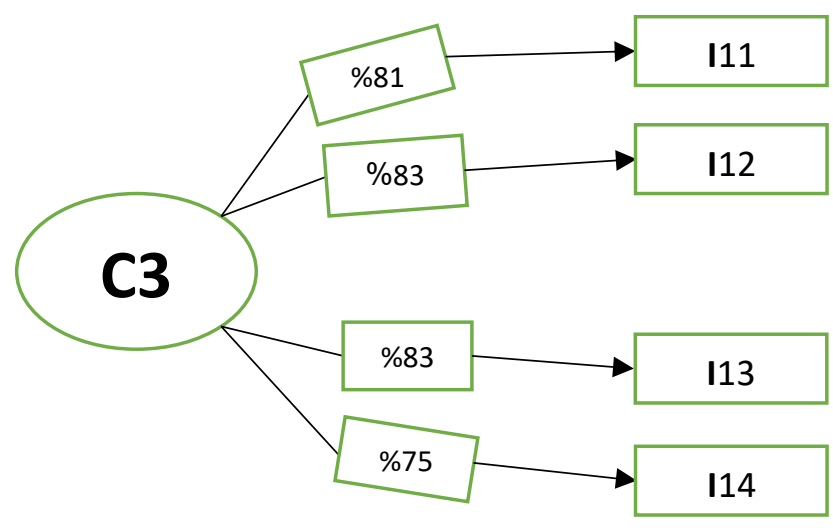

Diagram 3: Social Challenge Indexes

Cultural Challenges

Table 13 Approved indexes "Cultural Challenges" from Delphi technique

\begin{tabular}{|l|l|l|l|}
\hline Item & C4 : Cultural Challenges & $\begin{array}{l}\text { The } \\
\text { Consensus } \\
\text { percentage }\end{array}$ & Average Score \\
\hline I15 & $\begin{array}{l}\text { Public unacceptance of the cost of } \\
\text { using a green car relative to similar } \\
\text { cars }\end{array}$ & 87 & 4.33 \\
\hline & Average Cultural Challenges & & 4.33 \\
\hline
\end{tabular}

The consensus of experts shows that cultural challenges are influenced by an effective index as described in the table above. Schematically illustrated graphs illustrating the impact of cultural challenges in utilizing green technologies in the automobile industry. 


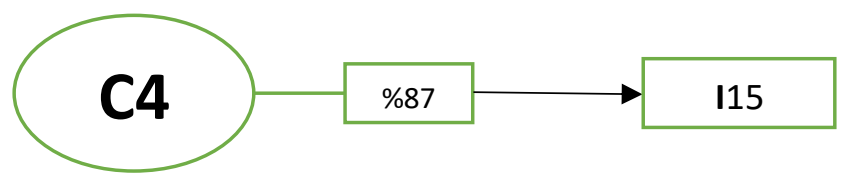

Diagram 4: Cultural Challenges Indexes

Technical and Technological Challenges

Table 13 Approved indexes "Cultural Challenges" obtained from Delphi technique

\begin{tabular}{|r|l|r|r|}
\hline Item & C5: Technical and technological Challenges & $\begin{array}{r}\text { The } \\
\text { Consensus } \\
\text { percentage }\end{array}$ & $\begin{array}{r}\text { Average } \\
\text { Score }\end{array}$ \\
\hline I16 & $\begin{array}{l}\text { Technology gap in application of green technologies } \\
\text { between the country and the international automakers }\end{array}$ & 89 \\
\hline I17 & $\begin{array}{l}\text { Unpreparedness of Green Vehicle Parts Manufacturers } \\
\text { Chain }\end{array}$ & 87.43 \\
\hline The average technical and technological challenges & 4.33 \\
\hline
\end{tabular}

The consensus of the experts shows that the technical and technological challenges are influenced by the two effective parameters as described in the table above. As illustrated in the diagram, it illustrates the state of play of the technical and technological challenges involved in utilizing green technologies in the automobile industry.

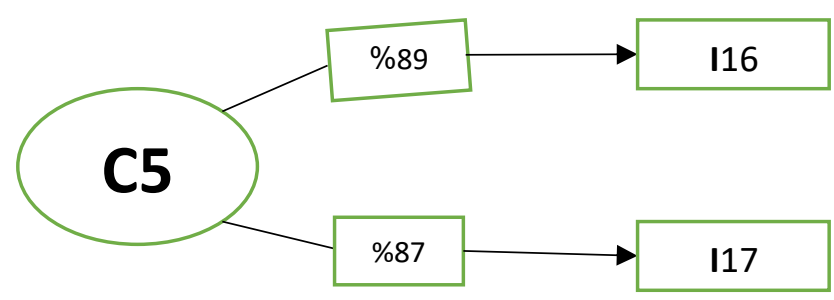


Diagram 5: Technical and Technological Indexes

The indexes for environmental

challenges have varied from 75 to 100 percent in terms of agreement and expert agreement, the closer the agreement to 100 indicates the severity and effectiveness of the indexes in terms of expert consensus.
On the other hand, based on the mean scores given by environmental experts, the environmental challenge subset shown schematically in Figure 1 radar can be deduced from the qualitative analysis.

\section{Environmental Challenges}

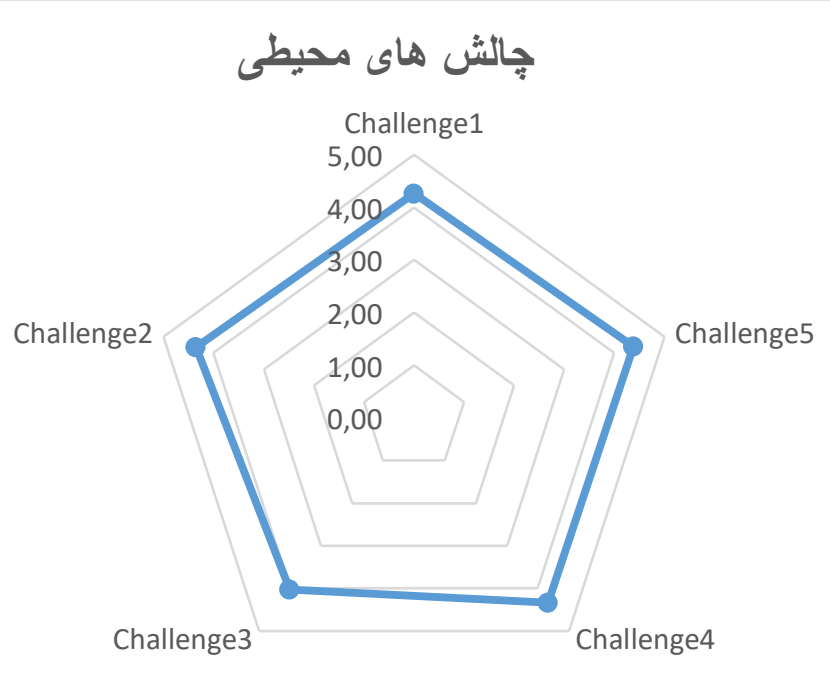

Figure 1: Radar diagram for the position of environmental challenge subset

According to the findings of the study, the challenges discussed are almost identical, while among the five environmental challenges, from the expert panel's point of view, technical and technological challenges have the 
highest percentage of agreement and

political challenges. Governmental in terms of number and volume of features has the most impact on the utilization of green technologies in the Iranian automobile industry.

B. Identifying and adopting the most important indexes and internal challenges
Approved indexes along with expert agreement percentages and averages based on the maximum score of "5" are presented in Table 55 to 5-10 with sub-categories of internal challenges.

Table 14: Approved indexes of "managerial structure Challenges" obtained from Delphi technique

\begin{tabular}{|l|l|l|l|}
\hline Item & C6: managerial structure & $\begin{array}{l}\text { The } \\
\text { Consensus } \\
\text { percentage }\end{array}$ & $\begin{array}{l}\text { Average } \\
\text { Score }\end{array}$ \\
\hline I18 & $\begin{array}{l}\text { Lack of strategies to perform the activates related to } \\
\text { green technology utilization }\end{array}$ & 89 & 4.43 \\
\hline I19 & $\begin{array}{l}\text { Lack of comprehensive roadmap to utilize green } \\
\text { technologies in automobile industry }\end{array}$ & 90 & 4.52 \\
\hline & The average managerial structure & & 4.48 \\
\hline
\end{tabular}

The consensus of the experts shows that the challenges of management structure are influenced by two effective indexes as described in the table above. The indexes are illustrated in the diagram and illustrate the impact of management structure challenges on the use of green technologies in the automobile industry. 


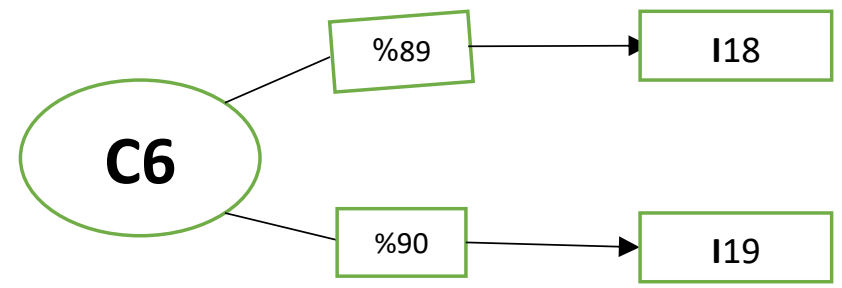

Diagram 6: Indexes for managerial structure challenges

Human Resources

Table 15: Approved indexes of "human resources challenges" obtained from Delphi technique

\begin{tabular}{|r|l|l|r|}
\hline Item & C7: Human Resources & $\begin{array}{l}\text { The } \\
\text { consensus } \\
\text { percentage }\end{array}$ & $\begin{array}{r}\text { The } \\
\text { average } \\
\text { score }\end{array}$ \\
\hline I20 & $\begin{array}{l}\text { Lack of required skills and capabilities in deploying } \\
\text { green technologies among senior executives }\end{array}$ & 4.05 \\
\hline I21 & $\begin{array}{l}\text { Lack / shortage of motivation among employees to } \\
\text { utilize green technologies }\end{array}$ & 75 & 3.76 \\
\hline & $\begin{array}{l}\text { Average human resources } \\
8\end{array}$ & 3.90 \\
\hline
\end{tabular}

The results of the consensus of experts show that human resource challenges are influenced by two effective indexes as described above.
The benchmarks are illustrated in graphs and illustrate the impact of human resource challenges on utilizing green technologies in the automobile industry.

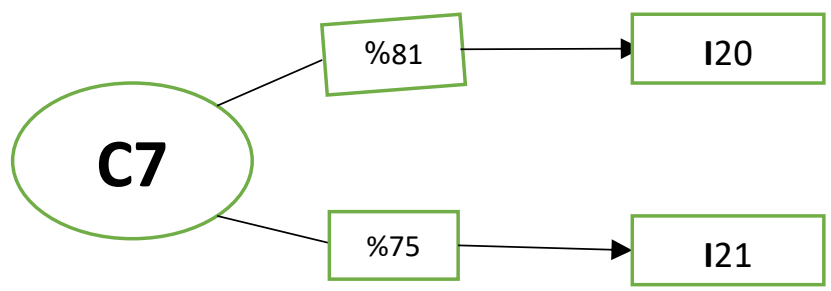


Figure 7- The indexes for human resources

Organization culture

Table 16: Approved indexes of "organizational culture challenges" obtained from Delphi technique

\begin{tabular}{|l|l|l|l|}
\hline Item & C8: Organizational culture & $\begin{array}{l}\text { Consensus } \\
\text { percentage }\end{array}$ & Average Score \\
\hline I22 & $\begin{array}{l}\text { Incredulity and lack of } \\
\text { understanding of the } \\
\text { paradigm shift caused by the } \\
\text { emergence and presence of } \\
\text { green technology in the } \\
\text { automobile industry }\end{array}$ & 85 & 4.24 \\
\hline Average organizational \\
culture
\end{tabular}

The consensus of experts shows and illustrates the state of play of the that the challenges of any organization impact of organizational challenges in are influenced by an effective utilizing green technologies in the benchmark as described above. The automobile industry.

benchmark is illustrated in the diagram

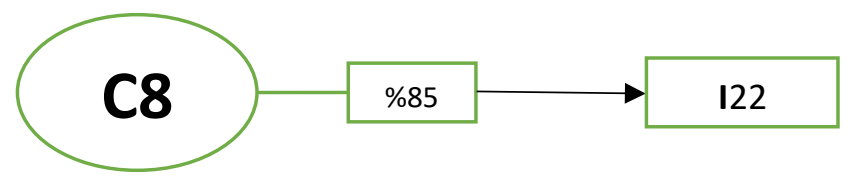

Diagram 8- Indexes for organizational culture challenges

\section{Organizational Structure}

Table 17: Approved indexes of "organizational structure challenges" obtained from Delphi technique 


\begin{tabular}{|l|l|l|l|}
\hline Item & C9: Organizational structure & $\begin{array}{l}\text { Consensus } \\
\text { percentage }\end{array}$ & $\begin{array}{l}\text { Average } \\
\text { Score }\end{array}$ \\
\hline I23 & $\begin{array}{l}\text { Lack of alignment with green technology strategies } \\
\text { and corporate macro strategies }\end{array}$ & 85 & 4.24 \\
\hline & Average organizational structure & & 4.24 \\
\hline
\end{tabular}

The results of the expert diagram and illustrates the impact of the consensus show that the challenge of organizational structure challenge on organizational structure is influenced by utilizing green technologies in the an effective index as described above. automobile industry.

The benchmark is illustrated in the

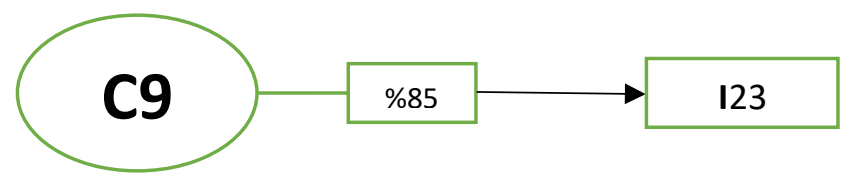

Diagram 9- Indexes for organizational structure challenges

Technical and technological capabilities

Table 18: Approved indexes of "technological and technical capabilities" obtained from Delphi technique

\begin{tabular}{|r|l|r|r|}
\hline Item & C10: Technical and technological capabilities & $\begin{array}{r}\text { Consensus } \\
\text { percentage }\end{array}$ & $\begin{array}{r}\text { Average } \\
\text { Score }\end{array}$ \\
\hline I24 & $\begin{array}{l}\text { Inadequate capabilities in manufacturing green } \\
\text { automobile }\end{array}$ & $\begin{array}{l}\text { Weaknesses and inadequacies of support systems and } \\
\text { utilization of green technologies in the automobile } \\
\text { industry } \\
\text { Average technical and technological capabilities }\end{array}$ & 85 \\
\hline & 4.44 \\
\hline
\end{tabular}


The consensus of the experts shows that the challenge of technical and technological capability is influenced by two effective factors as described above. The benchmarks are shown in graphs and illustrate the impact of the challenge of technical and technological capability on utilizing green technologies in the automobile industry.

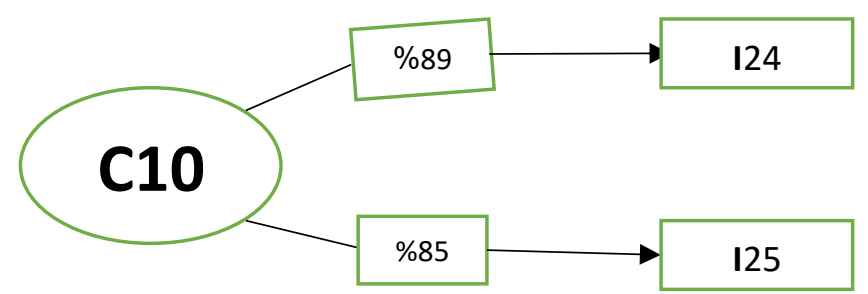

Diagram 10- Indexes of technical and technological capabilities

Likewise, it can be seen that the indexes of internal challenges in terms of percent agreement vary from 75 to 100 percent, the closer they are to 100 , indicating the importance and effectiveness of the indexes in the expert consensus.
On the other hand, based on the mean scores given by experts to internal challenges, the position of the internal challenges subset, which is schematically shown in Figure 2 and Figure 1, can be deduced from the qualitative analysis that can be made. 


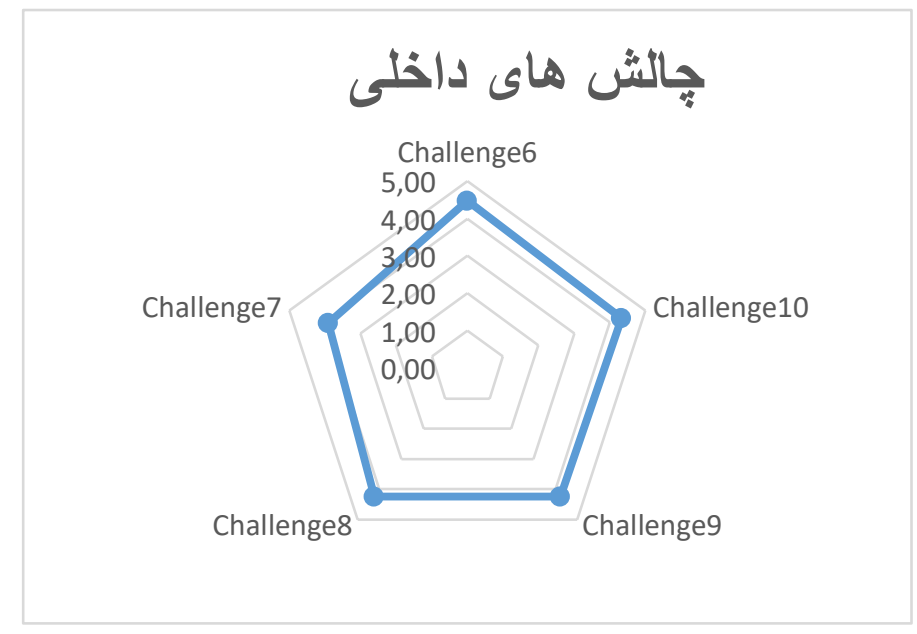

Figure 2: Radar diagram of the position of internal challenges subset

Similarly, it is observed that according to the research findings, the challenges under discussion are almost the same, however, among the five internal challenge factors, from the expert panel's point of view, the challenge of managing the highest percentage of agreement and in terms of number and volume. It is also subject to the highest number of attributes. In other words, according to the research results, among the internal challenges factors, from the experts' point of view, the challenges of management structure have the most impact on utilization of green technologies in Iranian automobile industry.

It is recalled that in this research, the methodology of exploratory qualitative research has been utilized by the consensus of experts to provide a basis for future quantitative research.

In other words, accurate assessment and judgment for both environmental and internal challenges is subject to quantitative analysis of the proposed model and the abovementioned characteristics.

Model of green technology in Iranian automobile industry 
Periódico do Núcleo de Estudos e Pesquisas sobre Gênero e Direito

Centro de Ciências Jurídicas - Universidade Federal da Paraíba V. 9 - $\mathrm{N}^{\circ} 02$ - Ano 2020 ISSN | 2179-7137 | http://periodicos.ufpb.br/ojs2/index.php/ged/index

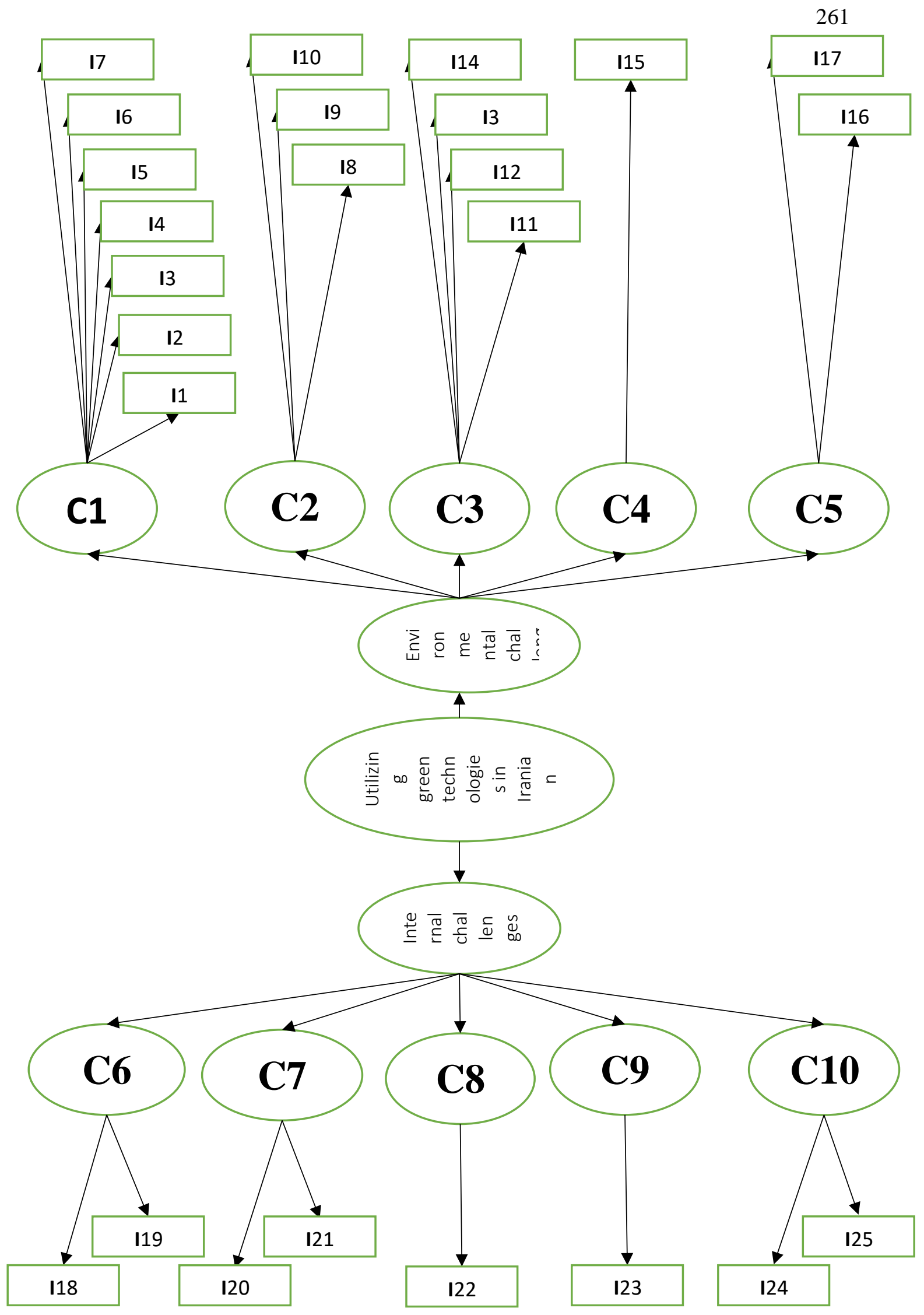




\section{References:}

Steven White, David A. Griffith., "Combining corporate and marketing strategy for global competitiveness," Marketing Intelligence \&Planning, p. Vol. 15/4 pp. 173-178, 1997.

Dess, Gregory G, Peter S. Davis, "Porter's (1980) generic strategies as determinants of strategic group membership and organizational performance," Academy of Management Journal, vol. 27.3, pp. 467-88, 1984.

verghes, K. Lewis, H, "environmental innovation in industrial packaging: a supply chain approach," international journal of production research, Vols. 45(18-19), pp. 4381-4401, 2007.

Nawrocka, Dagmara; Brorson, Torbjörn; Lindhqvist, Thomas, "ISO 14001 in environmental supply chain practices," Journal of Cleaner Production, vol. 17.16, pp. 1435-1443, 2009.

The goals and objectives of the automobile industry in the horizon of 2025; Ministry of Industries and Mines, 2009.
Karimi Kashani, Amir Hossein; Seyed Esfahani, Mirmahdi, Designing and Explaining the Model of Technology Development in the automobile Industry in Iran with Emphasis on Export Development Strategy, 2004.

Peter W. Stonebraker; Jianwen Liao, " Environmental turbulence, strategic orientation: Modeling supply chain integration," International Journal of Operations \& Production Management, vol. 24, pp. 1037 - 1054, 2004.

Karimi Kashani, Amir Hossein; Seyed Esfahani, Mirmahdi, Designing and Explaining the Model of Technology Development in the automobile Industry in Iran with Emphasis on Export Development Strategy, 2004.

Davodi, H., Iravani, H., Fami, H. S., \& Ameri, Z. D. (2017). Affecting Factors on Water Resources' Sustainability in case of small holding farmers, Alborz province, Islamic Republic of Iran. Advances in Bioresearch, 8(3). 
Jaffe; Adam, B; et al, "Environmental

Regulation and the Competitiveness of U.S. Manufacturing: What Does the Evidence Tell Us?" Journal of Economic Literature, Vols. 33, No. 1, pp. 132-163, 1995.

Anbari, M., Bagheri, R., \& Davodi, H. (2013). Survey of Social factors Effective on discontinuation of innovation in rural areas (Case Study: Drip irrigation Technology in Lorestan). Journal of Science and today's world, 2(5), 451-464.

Don, Kash; et al; (Advisory Panel),

"Advanced automobile Technology:

Visions of a Super-Efficient Family

Car," 1995 